www.jmscr.igmpublication.org

Impact Factor 5.244

Index Copernicus Value: 83.27

ISSN (e)-2347-176x ISSN (p) 2455-0450

crossref DOI: https://dx.doi.org/10.18535/jmscr/v4i12.134

Journal Of Medical Science And Clinical Research

IGM Publication

An official Publication of IGM Publication

\title{
Premature Rupture of Membranes-Clinico Epidemiological Perspective
}

\author{
Authors \\ Vinita Agrawal $^{1 *}$, Ashish Agrawal' ${ }^{2}$, Hitesh Parmar ${ }^{3}$, Prateek Porwal $^{4}$ \\ ${ }^{1,2}$ Professor, ${ }^{3,4}$ Postgraduates \\ Dept of Obstetrics and Gynecology and General Surgery, IMCHRC, Indore, M.P \\ *Corresponding Author \\ Email: Skyline.ashish@gmail.com
}

\begin{abstract}
Background: Aim of the study is to compare demographic data, study the outcome of pregnancy in patients with Premature Rupture of Membranes (PROM) and establish correlation between latency of PROM with outcome of pregnancy, maternal \& neonatal complications.

Material and Method: A hospital based prospective study was conducted from 01 Jan 2015 to 30 June 2016 on 209 cases of spontaneous premature rupture of membranes, in the Department of Obstetrics and Gynecology, Index Medical College Hospital \& Research Centre, Indore. Pregnant women, who presented with spontaneous premature rupture of membrane before onset of labor pains, were actively managed, by induction of labor, and those in labor were managed accordingly with single dose of prophylactic antibiotic. Mode of delivery and indication of CS along with maternal and neonatal outcome were recorded. The results were statistically analyzed regarding their correlation with latency with mode of delivery, perinatal morbidity and mortality and maternal morbidity.

Results: The mean age in our study was $23.13 \pm 3.31$ years, with $(67 \%)$ women were from rural area, $48.3 \%$ were booked and $62.7 \%$ was primigravida. In majority of the women, the latency period was between 0-6 hours (i.e. 43.5\%). In 87 (41.6\%) women the mode of delivery was LSCS, in 107 (51.2\%) mode of delivery was normal delivery. Most common indication for LSCS was fetal distress in 52 (59.8\%), Sepsis $(7.7 \%)$ and meconium aspiration syndromes (4.8\%) were the most common neonatal complications observed. Urinary tract infection was the most common maternal complications seen in our study, followed by sepsis and chorioamnionitis. Statistically significant association of latency period was found with mode of delivery, neonatal complication and puerperal complications $(P<0.05)$

Conclusion: PROM is a major cause for increased perinatal morbidity and mortality. As prevention of PROM is difficult due to obscurity of aetiology, one has to concentrate more on management of PROM to reduce its complications. To achieve this, proposed plan of "Aggressive management "that gives a high rate of successful vaginal deliveries and decreases the maternal and neonatal morbidity and mortality.

Keywords: Chorioamnionitis, Latency, PROM.
\end{abstract}

\section{Introduction}

Premature rupture of membranes is defined as rupture of membranes before the onset of labour, when it occurs before 37 completed weeks of gestation it is termed as preterm premature rupture of membranes (PPROM) and when it occurs after 37 completed weeks of gestation it is called term PROM $^{1}$. Premature rupture of membrane 
complicates approximately $8 \%$ of pregnancies (Williams, 24th edition) ${ }^{2}$ PPROM occurs in approximately $3 \%$ of pregnancies and is responsible for a third of all preterm birth ${ }^{3}$. PROM occurs in about 10 percent of all pregnancies ${ }^{4}$. In India, about 28 million deliveries occur annually and the incidence of PROM is $2.7 \%-17 \%$. At least $60 \%$ of cases of PROM occur at Term ${ }^{4}$. Among these in approximately $50 \%$ of cases labour starts spontaneously within 12 hours, $70 \%$ within 24 hours, $85 \%$ within 48 hours and $95 \%$ within 72 hours.

Prior to introduction of chemotherapeutic and antibiotic agents many maternity clinics pursued the policy of "the sun should never set more than once on the parturient with rupture of fetal membranes in the undelivered stage". The emphasis was placed on maternal outcome, for intrauterine infection at that time could only be treated supportively and all too often ineffectively. A third of these occurs prior to 37 weeks (PPROM) and is associated with higher perinatal morbidity and mortality. There is an enhanced risk of cord compression, prolapsed and infectious morbidity, particularly so if cesarean section becomes eventually necessary as maternal risks including chorioamnionitis, endometritis, abruption placenta and postpartum febrile morbidity ${ }^{6}$ increases. Approximately two-thirds of the patients with PROM are delivered within the next 4 days and the rest within 1 week. The time between the rupture of membranes and onset of labor (latent period) may extend from hours to days. Generally shorter the gestation period, longer the latent period (Arias $3^{\text {rd }}$ Edition, 2008) ${ }^{7}$. Premature rupture of membranes (PROM) remains a subject of great clinical relevance and intense interest and is day to day problem for each and every obstetrician. Despite exhaustive research, most aspects of PROM remain enigmatic. The mechanism of PROM is unknown, no standards for diagnosis exist and most facets of management are controversial. PROM is a major cause for prematurity which leads to increased perinatal morbidity and mortality. As prevention of PROM is difficult due to obscurity of aetiology, one has to concentrate more on management of PROM to reduce its complications. Ultimate goal of obstetrics is a pregnancy that results in healthy infant and minimally traumatized mother ( $\mathrm{M}$ Gandhi et al) ${ }^{8}$.

\section{Material and Method}

A hospital based prospective study was conducted from 01 Jan 2015 to 30 June 2016 on 209 cases of spontaneous premature rupture of membranes, in the Department of Obstetrics and Gynecology, Index Medical College Hospital \& Research Centre, Indore. The study is approved by Institutional Ethics committee. Pregnant women who presented with spontaneous premature rupture of membrane before onset of labor pains, either to out patients department or to labor room in emergency were included. Inclusion criteria was patients with gestational age $>37$ weeks $-<42$ weeks, age group 18-40 years, primigravida/ multigravida, singleton/twin pregnancy, malpresentation, confirmation of PROM by a speculum examination. Patients with gestational age $<37$ weeks or $>42$ weeksand age group $<18$ years OR $>40$ years were excluded.

Detailed history regarding age, educational and social status of patients and dietary and other habits of patients were recorded. Patients were classified into booked/unbooked according to number of antenatal visits. Detailed present and past obstetric history, general, physical and obstetrical examination of patients was conducted. PROM was confirmed, if on speculum examination, there was amniotic fluid seen draining through the cervical OS along with reduced amniotic fluid index on ultrasound. In equivocal cases nitrazene test was performed for confirmation. Laboratory investigation included complete blood count and grouping was done. In cases of suspected infection high vaginal swab culture and sensitivity was sent.

All patients with PROM were actively managed, by induction of labor, and those who are in labor managed accordingly with single dose of 
prophylactic antibiotic. Latency period [Time interval between rupture of membranes and the onset of regular uterine contraction], mode of delivery and maternal and neonatal outcome were recorded including composite major neonatal and maternal morbidity. The results were statistically analyzed regarding their correlation with latency with mode of delivery, perinatal morbidity and mortality and maternal morbidity

\section{Result}

In Table No 1, there were 46 (22\%) women in the age group 18-20 years, $134(64.1 \%)$ in the age group 21-25 years, 20 (9.6\%) in the age group 2630 years and $9(4.3 \%)$ in the age group $>30$ years. The mean age in our study group was $23.13 \pm 3.31$ years. There were $140(67 \%)$ women who were from rural area and 69 (33\%) were from urban area. There were $101(48.3 \%)$ women who were booked, while $108 \quad(51.7 \%)$ women were unbooked. Majority of the women in our study were from rural area, unbooked and primigravida $131(62.7 \%)$, followed by gravida $2-48(23.0 \%)$ and gravida $3-20(9.6 \%)$.

Table No. 1 Distribution of women according to demographic factors

\begin{tabular}{|l|c|c|}
\hline Demographic factor & Number & Percentage \\
\hline Age Group & & \\
\hline 18-20 years & 46 & 22.0 \\
\hline 21-25 years & 134 & 64.1 \\
\hline 26-30 years & 20 & 9.6 \\
\hline >30 years & 9 & 4.3 \\
\hline Gravidity & & \\
\hline G1 & 131 & 62.7 \\
\hline G2 & 48 & 23.0 \\
\hline G3 & 7 & 9.6 \\
\hline G4 & 3 & 3.3 \\
\hline G5 & 7.4 \\
\hline
\end{tabular}

In Table No 2, in 91 (43.5\%) women the latency period was 0-6 hours, in $45(21.5 \%)$ women the latency period was 7-12 hours, in $16(7.7 \%)$ women the latency period was 13-18 hours, in 14 (6.7\%) women latency period was 19-24 hours and in $43(20.6 \%)$ women it was $25-48$ hours. In majority of the women, the latency period was between 0-6 hours. In $87(41.6 \%)$ women the mode of delivery was LSCS, in 107 (51.2\%) mode of delivery was normal delivery, in 4 (1.9\%) women mode of delivery was assisted breech, in 2 (1\%) it was forceps delivery and in $9(4.3 \%)$ woman it was VBAC. Statistically significant association was found between latency period and mode of delivery $(\mathrm{P}<0.05)$ showing that mode of delivery is dependent on the latency period.

Table No. 2 Association of latency period with mode of delivery

\begin{tabular}{|l|c|c|c|c|c|c|}
\hline \multirow{2}{*}{$\begin{array}{l}\text { Latency } \\
\text { Period }\end{array}$} & $\begin{array}{c}\text { Assisted } \\
\text { Breech }\end{array}$ & $\begin{array}{c}\text { Forceps } \\
\text { Delivery }\end{array}$ & LSCS & $\begin{array}{c}\text { Normal } \\
\text { Vaginal } \\
\text { Delivery }\end{array}$ & VBAC & $\begin{array}{c}\text { TOT } \\
\text { AL }\end{array}$ \\
\hline $\begin{array}{l}0-6 \\
\text { hours }\end{array}$ & 4 & 0 & 32 & 46 & 9 & 91 \\
\hline $\begin{array}{l}7-12 \\
\text { hours }\end{array}$ & 0 & 1 & 9 & 35 & 0 & 45 \\
\hline $\begin{array}{l}13-18 \\
\text { hours }\end{array}$ & 0 & 0 & 8 & 8 & 0 & 16 \\
\hline $\begin{array}{l}19-24 \\
\text { hours }\end{array}$ & 0 & 0 & 8 & 6 & 0 & 14 \\
\hline $\begin{array}{l}25-48 \\
\text { hours }\end{array}$ & 0 & 1 & 30 & 12 & 0 & 43 \\
\hline Total & 4 & 2 & 87 & 107 & 9 & 209 \\
\hline$\chi 2=45.806, d f=16, P$ value $=0.001$, Significant & \\
\hline
\end{tabular}

In Table No 3, LSCS was done in 87 women. Of these 87 women, most common indication for LSCS was fetal distress in 52 (59.8\%), failed induction in 17 (19.6\%), CPD in $9(10.3 \%)$ and previous LSCS in $9(10.3 \%)$ women.

Table No. 3 Distribution of women according to indication for LSCS

\begin{tabular}{|l|c|c|}
\hline Indication for LSCS & Number & Percentage \\
\hline Fetal distress & 52 & 59.8 \\
\hline Failed induction & 17 & 19.6 \\
\hline CPD with & 9 & 10.3 \\
\hline $\begin{array}{l}\text { Previous LSCS } \\
\text { scar tenderness }\end{array}$ & 87 & 10.3 \\
\hline Total & & 100.0 \\
\hline
\end{tabular}

In Table No 4, in 174 (83.3\%) neonates there was no complications, in $16(7.7 \%)$ neonates sepsis was seen, in $10(4.8 \%)$ neonates meconium aspiration syndrome was seen, in $3(1.4 \%)$ there was pneumonia, $2(1 \%)$ neonates expired, $2(1 \%)$ had intrauterine death and in $2(1 \%)$ there was respiratory distress syndrome. Sepsis and meconium aspiration syndromes were the most 
common neonatal complications observed. Statistically significant association was found between latency period and neonatal complications $(\mathrm{P}<0.05)$ showing that neonatal complications are dependent on the latency period.

Table No. 4 Association of latency period with neonatal complications

\begin{tabular}{|c|c|c|c|c|c|c|c|c|}
\hline \multirow{2}{*}{$\begin{array}{l}\text { Latency } \\
\text { Period }\end{array}$} & \multicolumn{7}{|c|}{ Neonatal Complications } & \multirow[t]{2}{*}{ Total } \\
\hline & 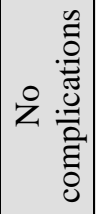 & $\frac{n}{\tilde{0}}$ & $\sum_{\Sigma}^{\infty}$ & 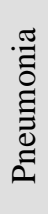 & $\supseteqq$ & $\frac{.0}{0}$ & $\tilde{2}$ & \\
\hline $\begin{array}{l}0-6 \\
\text { hours }\end{array}$ & 83 & 6 & 1 & 0 & 0 & 1 & 0 & 91 \\
\hline $\begin{array}{l}7-12 \\
\text { hours }\end{array}$ & 43 & 1 & 1 & 0 & 0 & 0 & 0 & 45 \\
\hline $\begin{array}{l}\text { 13-18 } \\
\text { hours }\end{array}$ & 13 & 1 & 1 & 0 & 1 & 0 & 0 & 16 \\
\hline $\begin{array}{l}19-24 \\
\text { hours }\end{array}$ & 11 & 0 & 2 & 0 & 1 & 0 & 0 & 14 \\
\hline $\begin{array}{l}25-48 \\
\text { hours }\end{array}$ & 24 & 8 & 5 & 3 & 0 & 1 & 2 & 43 \\
\hline Total & 174 & 16 & 10 & 3 & 2 & 2 & 2 & 209 \\
\hline
\end{tabular}

In Table No 5, In our study, in 64 (30.6\%) women no maternal complications were seen, in 102 $(48.8 \%)$ women urinary tract infection was seen, in $22(10.5 \%)$ sepsis was seen, in $15(7.2 \%)$ chorioamnionitis was seen, in $15(7.2 \%) \mathrm{PPH}$ was seen and in $5(2.4 \%)$ patient respiratory tract infection was seen. Urinary tract infection was the most common maternal complications seen in our study, followed by sepsis and chorioamnionitis. Statistically significant association was found between latency period and puerperal complications $(\mathrm{P}<0.05)$ showing that puerperal complications are dependent on the latency period.
Table No. 5 Association of latency period with maternal complications

\begin{tabular}{|c|c|c|c|c|c|c|c|}
\hline \multirow{2}{*}{$\begin{array}{l}\text { Latency } \\
\text { Period }\end{array}$} & \multicolumn{6}{|c|}{ Maternal Complications } & \multirow[t]{2}{*}{ Total } \\
\hline & 之. & 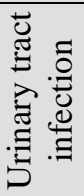 & $\begin{array}{l}\frac{\infty}{\omega} \\
\tilde{\infty} \\
\tilde{\omega}\end{array}$ & 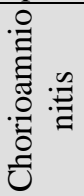 & $\frac{\pi}{2}$ & 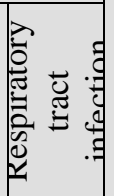 & \\
\hline $0-6$ hours & 26 & 51 & 8 & 3 & 3 & 0 & 91 \\
\hline $7-12$ hours & 12 & 32 & 1 & 0 & 0 & 0 & 45 \\
\hline $\begin{array}{l}13-18 \\
\text { hours }\end{array}$ & 6 & 7 & 1 & 2 & 0 & 0 & 16 \\
\hline $\begin{array}{l}19-24 \\
\text { hours }\end{array}$ & 7 & 5 & 0 & 2 & 0 & 0 & 14 \\
\hline $\begin{array}{l}25-48 \\
\text { hours }\end{array}$ & 13 & 7 & 12 & 8 & 2 & 1 & 43 \\
\hline Total & 64 & 102 & 22 & 15 & 5 & 1 & 209 \\
\hline
\end{tabular}

\section{Discussion}

\section{Demographic factors (Table No. 1):}

In present study maximum numbers 134(64.1\%) of women were between 2 1-25 years and 20(9.6\%) were between 26-30 years. The mean age in our study group was $23.13 \pm 3.31$ years which is comparable to study by Patil $\mathrm{S}$ et $\mathrm{al}^{9}$ i.e. $23 \pm 3.5$ years. In present study $73.3 \%$ belongs to age group 21-30 years.comparable to Gandhi $\mathrm{M}$ et $\mathrm{al}^{8} 77.6 \%$ women with prom belong to age group 21-30 years and. by Milad,M.M.Gahwagi et $\mathrm{al}^{10}$ maximum $61 \%$ women belong to age group 21-30 years and Maximum cases were in 21-30 years, due to the fact that Indian women complete their child bearing by $3^{\text {rd }}$ decade. Shivamurty et al ${ }^{11}$ The incidence was found to be higher in case of young pregnant women. Hence it is evident from available literature and present study that no age is immune for PROM. In present study, maximum $140(67 \%)$ cases of PROM belong to rural area while only $69(33 \%)$ cases to urban area. In a similar study by Gandhi $\mathrm{M}$ et $\mathrm{al}^{8}, 61.7 \%$ cases of PROM belonged to rural area and $38.3 \%$ to urban area. Shivamurty H.M.et al ${ }^{11}$ the incidence was found to be higher in case of rural women. Residential area definitely makes difference in incidence of PROM. In rural area because of unhygienic conditions, there are more chances of infection, which is an independent risk factor for $\operatorname{PROM}^{(12,13,14,15)}$. 
In present study, out of 209 patients majority of the women 108 (51.7) were unbooked, and 101(48.3) were booked. Patient delivered at our institute are equally distributed between booked and unbooked referred, as no other tertiary centre available nearby, and unavailability of trained staff in nearby PHC,s. In similar study by Shweta et $\mathrm{al}^{9}$.contrary to it $69 \%$ cases was booked, probably because of higher education and more awareness in Karnataka While in study by V.revathi et al ${ }^{19} 78 \%$ cases was unbooked and only $22 \%$ booked. Most probable cause is booked cases have awareness regarding risk factor. In present study the maximum pregnant women with PROM i.e. - $62.7 \%(131)$ are primigravida \& only $37.3 \% \quad(78)$ are multigravida.__t is comparable to various studies .Gandhi $\mathrm{M}$ et $\mathrm{al}^{8}$ $(60.57 \%)$, Shweta et $\mathrm{al}^{9}(53 \%)$ and Milad, M.M.Gahwagi et $\mathrm{al}^{10}(48 \%)$. Most of cases at our institute are referred and unbooked, as it's the only tertiary health centre in rural area nearby, mostly primigravida patients were referred as multigravida delivered at PHC's and CHC's. (Shivamurty et al ${ }^{11)}$ The incidence was found to be higher in case of primigravida. According to Aktar et $\mathrm{al}^{17}(45 \%)$ chances of increased chances of increased sexual activity and increased genital infection are most common among primigravida.

\section{Association of latency period with mode of delivery (Table No.2)}

In present study maximum 104 (49.8\%) women were the latency period of 0-6 hours, while 47 $(22.5 \%)$ women were the latency period of 7-12 hours, \& only in $27(12.9 \%)$ women it was $\geq$ 1day. In majority of the women, the latency period was between 0-6 hours \& $87.1 \%$ ( 182) cases were with latency period up to $24 \mathrm{hrs}$. Hence in our study total no of patient having latency period up to $24 \mathrm{hrs}$ was $87.1 \%$ which is comparable to Patil et $\mathrm{al}^{9}(76 \%)$, Russels et $\mathrm{al}^{18}(80 \%)$ and Gandhi M et $\mathrm{al}^{8}(92.5 \%)$. Our institute adopted the policy of aggressive management for the cases of term PROM who reported without labor pain, so all patients delivered within 48 hours.
In the present study, maximum number of women 107 (51.19\%) had delivered normally, while $87(41.6 \%)$ were delivered by caesarean section. $2(1 \%)$ pregnant mother delivered by instrumental deliveries, $4(1.9 \%)$ by assisted breech and 9(4.3\%) by VBAC. In our study percentage of caesarean section directly associated with latency period.

Statistically significant association was found between latency period and mode of delivery $(\mathrm{P}<$ $0.05)$ showing that mode of delivery is dependent on the latency period. ( $P$ value $=0.0001$, Significant).As latency increases more liquor will be drained out resulting in oligohydramnios/dry labour which causes fetal distress ultimately land up in to LSCS.

Robson et al ${ }^{19}$. suggested that a significant amount of amniotic fluid needs to drain rapidly and continuously for oligohydramnios to occur, especially because the fluid is replaced to varying degrees by the fetus. Studies shows low CS rate are mostly from states whose performance in antenatal care, Referral system are good, and women education is higher. While in present study centre is located away far from city\& only tertiary health care centre, covering large number of sub centre \&PHC's.\& from Table $2 \& 3$ it is evident that mostly women in study are rural and low socioeconomic status, so delayed referral is main cause. This difference is may be due to large number i.e.46 (22.1\%) cases were having indication like previous LSCS or reported with fetal distress. Lower rate of instrumental deliveries also account for higher rate of CS as all that cases taken for caesarean section ultimately.

\section{Distribution of women according to indication for LSCS (Table No 3)}

In present study $41.6 \%$ ( 87) required LSCS and most common indication was fetal distress (59.8\%) and least common are CPD and Previous LSCS (both 10.3\%). Results in our study are comparable to following studies: 


\begin{tabular}{|l|c|c|c|c|}
\hline Indication & $\begin{array}{c}\text { Patil S } \\
\text { et al }^{9}\end{array}$ & $\begin{array}{c}\text { Gandhi } \\
\mathrm{M} \mathrm{et} \mathrm{al}^{8}\end{array}$ & $\begin{array}{c}\text { Present } \\
\text { study }\end{array}$ & $\begin{array}{c}\text { Milad et } \\
\mathrm{al}^{10}\end{array}$ \\
\hline Fetal distress & $51.85 \%$ & $50 \%$ & $59.8 \%$ & $14.3 \%$ \\
\hline Failed induction & --- & $31.8 \%$ & $19.6 \%$ & $50 \%$ \\
\hline CPD & $14.80 \%$ & - & $10.3 \%$ & - \\
\hline $\begin{array}{l}\text { Previous LSCS } \\
\text { with ST }\end{array}$ & $11.11 \%$ & - & $10.3 \%$ & $3.6 \%$ \\
\hline
\end{tabular}

Fetal distress is most common indication in most of the studies, including present study, except by Milad at $\mathrm{el}^{10}$.In cases of prolong leaking, liquor will drain out resulting in oligohydramnious, which causes fetal distress. Cord compression, cord prolapse, are other causes of fetal distress. Failed induction was $2^{\text {nd }}$ most common indication for LSCS in most of the studies except by Milad et al ${ }^{10}$ in which it was the most common cause. Induction in cases with unfavourable score (Bishop's) lands up in failure, Revathi et $\mathrm{al}^{16}$ LSCS rate double in the patient with unfavourable score than favourable. Weak scare in previous LSCS, birth spacing <3 years, leads to repeat LSCS,

\section{Association of latency period with neonatal complications (Table No 4)}

In present study $174(83.3 \%)$ neonates there was no complications, in $16(7.7 \%)$ neonates sepsis was seen, in $10(4.8 \%)$ neonates meconium aspiration syndrome was seen, in $3(1.4 \%)$ there was pneumonia, $2(1 \%)$ neonates expired, $2(1 \%)$ had intrauterine death and in $2(1 \%)$ there was respiratory distress syndrome. Sepsis and meconium aspiration syndromes were the most common neonatal complications observed. Sepsis may be due to low birth weight and low apgar babies, who require NICU stay, where iatrogenic sepsis is common. As institute is tertiary health care centre, mostly patients are referred from periphery with fetal distress, and meconium stained liquor for surgical intervention so incidence of neonate developing meconium aspiration syndrome increases.

Hauback found that latent period is more important factor than GA for the risk of neonatal infection. Latency period is directly related to perinatal morbidity and is comparable to study by
Revathi et $\mathrm{al}^{16}$. It was observed that with latency period less than $12 \mathrm{hrs}$, perinatal morbidity was $8 \%$ in our study and $14.28 \%$ in Revathi et $\mathrm{al}^{16}$, which rise as period increased more than $24 \mathrm{hrs} 36 \%$ and $30.55 \%$ respectively.

\section{Association of latency period with maternal complications (Table No 5)}

In our study, in $64(30.6 \%)$ women no maternal complications were seen, in $102(48.8 \%)$ women urinary tract infection was seen, in $22(10.5 \%)$ sepsis was seen, in $15(7.2 \%)$ chorioamnionitis was seen, in $5(2.45 \%) \mathrm{PPH}$ was seen and in 1 $(0.5 \%)$ patient respiratory tract infection was seen. Urinary tract infection was the most common maternal complications seen in our study, followed by sepsis and chorioamnionitis.

According to Revathi ${ }^{16}$, the lesser the time interval between the rupture of membranes and delivery, the lesser was the maternal and perinatal morbidity and mortality. The incidence of chorioamnionitis infection is more if the latent period is more than 24 hours. $1.7 \%$ of his patients developed fever within 24 hours after PROM, $7.5 \%$ between $24-48$ hours and $8.6 \%$ beyond 48 hours (Burchell RC) ${ }^{20}$. Statistically significant association was found between latency period and puerperal complications $(\mathrm{P}<0.05)$ showing that puerperal complications are dependent on the latency period. Hence it was observed that with latency period less than $12 \mathrm{hrs}$, maternal morbidity was $11 \%$ in our study and $3.33 \%$ in Revathi et $\mathrm{al}^{16}$, which rise as period increased more than 24 hrs $53.4 \%$ and $75.86 \%$ respectively

\section{Conclusion}

Premature rupture of membranes (PROM) remains a subject of great clinical relevance and intense interest and is day to day problem for each and every obstetrician. Despite exhaustive research, most aspects of PROM remain enigmatic. The emphasis is placed on fetal welfare and here the subtleness of intrauterine infection comes to core. Certainly fetal infection may occur when maternal vital signs are normal. 
PROM is more in age group 2125,primigravida,unbooked and rural population.In majority of the women, the latency period was between 0-6 hours \& $87.1 \%$ ( 182) cases were with latency period up to 24hrs. Maximum number of women 107 (51.19\%) had delivered normally, while 87(41.6\%) were delivered by caesarean section. Most common indication for CS was fetal distress. Statistically significant association was found between latency period with mode of delivery,maternal complicacation and neonatal complication

PROM is a major cause for prematurity which leads to increased perinatal morbidity and mortality. As prevention of PROM is difficult due to obscurity of aetiology, one has to concentrate more on management of PROM to reduce its complications. To achieve this, the main objective of the obstetrician should be early screening, adequate antenatal visits and improvement of general condition of the mother, identifying risk factors, treating associated complications, correct diagnosis of rupture of membranes. Antibiotic administration and induction of delivery i.e. proposed plan of "Aggressive management "that gives a high rate of successful vaginal deliveries and decreases the maternal and neonatal morbidity and mortality. The Ultimate goal of obstetrics is a pregnancy that results in healthy infant and minimally traumatized mother but the fact that fetal and neonatal results should not be judge by peri-natal mortality rates only, but rather should include the ultimate outcome of the infant some months or a year or more, following birth.

\section{References}

1. Cunningham,Leveno,Bloom,Spong,Dashe, Hoffman, Preterm Birth.Chap.36.In: Cunningham, Leveno, Bloom,Spong, Dashe, Hoffman (Ed) Williams Obstetrics. $22^{\text {nd }}$ edition,New York:McGraw Hill Education,2005, pp 855

2. Cunningham,Leveno,Bloom,Spong,Dashe, Hoffman, Abnormal labor.Chap.23.In: Cunningham,Leveno,Bloom,Spong,Dashe,
Hoffman (Ed) Williams Obstetrics.24 ${ }^{\text {nd }}$ edition, New York: McGraw Hill Education, 2014, pp 462

3. Simhan HN,.Canavan PC:PPROM: diagnosis, evaluation \& management strategies.BJOG 2005;112 (1) 32-7.

4. Corolyn,L Gegor, Helan vermay, Jan M Kriebs; Varneys text book of midwifery: 4th edition, 2005, Rajendra K Arya New Delhi: 863 - 866 .

5. Scott C, Chavez GM, Atrash H, Taylor D, Shah RS, Rowley D. Hospitalizations for severe complications of pregnancy, 19871992. Obstetrics and Gynecology 1997; 90:22 - 9

6. Amira El-Messidi, Alan Cameron et al: Diagnosis of Premature rupture of membranes : Inspiration from the past and insights for the future, JUNE JOGC JUIN 2010 , page 562-567

7. Arias,practical guide to High Risk Pregnancy \& Delivery, $3^{\text {rd }}$ Ed,New Delhi:Elsevier 2008

8. Gandhi M,,Shah F, Panchal C.obstetric outcomes in Premature Rupture of membrane. The internet journal of gynecology and obstetric.2012; 16 (2)

9. Patil S,Patil V.Maternal and foetal outcome in premature rupture of membranes.IOSR-JDMS,Dec 2014;13(12) pp 56-83

10. Milad M.M.Gahwagi,Musa O.Mona Atia.Premature Rupture of membranes characteristics, determinants.and Outcome of in Benghazi,Libya:open Journal of Obstetrics and Gynecology,2015,5.494504.

11. Shivamurty H. M.**, N. Spandana Y. Anusha Sunkara*, Ahswini Konin*, V. Sridivya Chowdary, Comparative prospective study of outcome between aggressive and expectant management of premature rupture of membranes: , Statperson Publications, International Journal of Recent Trends in Science And 


\section{JMSCR Vol||04||Issue||12||Page 15130-15137||December}

Technology, 2015,ISSN 2277-2812 EISSN 2249-8109;14 ( 2)

12. Minkoff H, Grunebaum AN, Schwarz RH, Feldman J, Cummings M, Crombleholme W, Clark L, PringleG,McCormack WM Risk factors for prematurity and premature rupture of membranes: a prospective study of the vaginal flora in pregnancy. (PMID:6391179)American Journal of Obstetrics and Gynecology [1984, 150(8):965-72]

13. Hargar JH, Hsing AW, Tuomala RE, Gibbs RS, Mead PB, Eschenbach DA, Knox GE, Polk BF, Risk Factors for preterm premature rupture of fetal membranes: a multicentric case control study. American journal of obs.and gynecol.1990:163:130-7

14. Gomez R, Romero R, Edwin SS, David C Pathogenesis of preterm labor and preterm premature rupture of membranes associated with intrauterine infection. Infectious Disease Clinics of North America: 1997:11(1); 135-176

15. Romero R, Quintero R, et al. Intraamniotic infection and onset of labor in PPROM. Am J Obstetric Gynecology. 1988c. 159.

16. Revathi V,Sowjanya R,LLavanya S..Maternal and perinatal outcome in Premature Rupture of Membranes at term.IOSR-JDMS 2015(15):12-1520

17. Aktar MS, Degan JS, Aktar UA, D Sharam. PROM: Study of 300 cases and review of literature. J Obstet \& Gynecol of India. 1980; 30: 81.

18. Russell KP, Anderson GVT. The aggressive management of ruptured membranes. Am J Obstet Gynecol 1962; 83: 930-1962.

19. Manning FA, Hill FM, Platt LD. Qualitative amniotic fluid volume determination by ultrasound. Antepartum detec- tion of intrauterine growth retardation. Am J Obstet Gynecol 1981; 139:254-8.

20. Burchell RC. Premature spontaneous rupture of the membranes. Am J Obstet Gynec 1964; 88: 251. 